\title{
Endocrine Consequences of Continuous Antiestrogen Therapy with Tamoxifen in Premenopausal Women
}

\author{
Barry M. Sherman, Frederick K. Chapler, Kent Crickard, and \\ DoRothy Wycoff, Departments of Internal Medicine, Obstetrics and \\ Gynecology, and Pathology, University of Iowa College of Medicine, \\ Iowa City, Iowa 52242
}

\begin{abstract}
A B S T R A C T Daily administration of estrogen antagonists to premenopausal women has been incorporated into the adjuvant treatment of breast cancer. We have studied the changes in reproductive hormones, pituitary responses to hypothalamic-releasing hormones, and endometrial histology during treatment with the antiestrogen tamoxifen in five healthy, premenopausal women. These studies were carried out during one menstrual cycle before and during two cycles of antiestrogen treatment. All subjects continued to have regular menses with biphasic basal body temperature records. During treatment, estradiol $\left(E_{2}\right)$ levels were increased but followed the usual pattern reflecting follicular maturation and corpus luteum formation. The mean $\mathrm{E}_{2}$ concentration at the midcycle peak and during the luteal phase was twice that observed during the non-treatment cycle. By contrast, the concentrations and secretory patterns of luteinizing hormone and follicle-stimulating hormone were not greatly changed, and the gonadotropin responses to gonadotropin-releasing hormone were not suppressed.

Endometrial biopsies obtained during the follicular phase of control and tamoxifen treatment cycles showed no differences whereas biopsies obtained during the luteal phase of tamoxifen cycles uniformly showed a lack of changes attributed to progesterone action with no progression of histologic changes beyond those expected on day 7-8 of the luteal phase.
\end{abstract}

These observations are consistent with maturation of multiple ovarian follicles, a surprising finding considering the normal gonadotropin concentrations. The retarded development of the endometrium in the presence of supranormal serum $\mathrm{E}_{2}$ and progesterone concentrations is a morphologic demonstration of the antiprogestational effect of antiestrogens. The lack of gonadotropin suppression in the presence of hyper-

Received for publication 11 December 1978 and in revised form 20 April 1979. estrogenemia suggests a major antiestrogen action on the hypothalmus and pituitary gland.

\section{INTRODUCTION}

Antiestrogens have recently been incorporated into the medical management of breast cancer for treatment of metastatic disease and in clinical trials of prophylactic adjuvant therapy $(1,2)$. The hormonal responses to short courses of an estrogen antagonist used for ovulation induction have been described (3). The endocrine consequences of daily antiestrogen therapy in women are largely unexplored. We considered that the effects of continuous antiestrogen therapy on hypothalamic-pituitary-ovarian regulation in premenopausal women might be especially profound with implications for both breast cancer treatment and normal physiology.

\section{METHODS}

Five healthy, paid volunteers, ages $28-43$, were recruited from among employees of University Hospitals. All subjects gave a history of regular menses. To avoid any consequences for future fertility, women were chosen who were not desirous of additional pregnancies; two had had tubal ligations and the husbands of the other women had had vasectomies.

A 10-ml blood sample was obtained on alternate days for three consecutive menstrual cycles for determination of luteinizing hormone (LH), ${ }^{1}$ follicle-stimulating hormone $(\mathrm{FSH})$, estradiol $\left(\mathrm{E}_{2}\right)$, and progesterone $(\mathrm{P})$. In two subjects 12-h/overnight urine specimens were collected. After the first cycle, during which no treatment was given, subjects received tamoxifen, $10 \mathrm{mg}$, twice daily, for two, and one subject for three consecutive cycles. Basal body temperatures were recorded daily throughout the study.

\footnotetext{
${ }^{1}$ Abbreviations used in this paper: $\mathrm{E}_{2}$, estradiol, $\mathrm{FSH}$, folliclestimulating hormone; GnRH, gonadotropin-releasing hormone; LH, luteinizing hormone; $\mathrm{P}$, progesterone; PRL, prolactin; TSH, thyroid-stimulating hormone; TRH, thyrotropinreleasing hormone.
} 
The subjects were admitted to the Clinical Research Center during the follicular phase of the first (nontreatment) cycle and again during the second cycle of tamoxifen therapy. On those occasions, 5-ml blood samples were obtained at 20 -min intervals for $3 \mathrm{~h}$ followed by the simultaneous administration of $50 \mu \mathrm{g}$ of gonadotropin-releasing hormone $(\mathrm{GnRH})$ and $500 \mu \mathrm{g}$ of thyrotropin-releasing hormone (TRH) to assess basal and stimulated concentrations of $\mathrm{LH}, \mathrm{FSH}$, thyroid-stimulating hormone (TSH), and prolactin (PRL). An endometrial biopsy was done during each admission and again during the luteal phase of the second cycle of tamoxifen therapy. Each subject was maintained on ferrous sulfate and experienced no reduction of hematocrit during the study.

The sera and urine were stored at $-20^{\circ} \mathrm{C}$. The serum $\mathrm{LH}$, FSH, TSH, and PRL were measured by radioimmunoassay using a standard double-antibody system and agents supplied by the National Pituitary Agency, Baltimore, Md. (4-7). All samples for each hormone were measured in a single assay. Gonadotropin results were expressed as nanograms per milliliter of the reference preparation LER-907. Serum $E_{2}$ and $P$ were measured using specific antisera generously supplied by Dr. Gordon Niswender (8). Urinary estrone, $\mathrm{E}_{2}$, and estriol were measured by radioimmunoassay at the Worcester Foundation for Experimental Biology, Shrewsbury, Mass.

Endometrial biopsies were performed with a Novak curette and specimens were fixed in $10 \%$ buffered formalin. Routine sections, stained with hematoxylin and eosin were evaluated by criteria established by Noyes et al. for dating of endometrial tissue (9). All samples were evaluated as routine surgical specimens with no knowledge of the patient's treatment status.

Statistical methods included the paired $t$ test and analysis of variance, as noted in the text.

\section{RESULTS}

All women continued to menstruate while taking tamoxifen, and basal body temperature records showed a normal thermal shift during each cycle. There was no change in mean basal temperature during tamoxifen treatment. Neither the mean cycle length nor the duration of the follicular or luteal phases was changed significantly by the antiestrogen treatment (Table I). However, three cycles during tamoxifen treatment were 19,22 , and $20 \mathrm{~d}$, due in each case to diminished length of the follicular phase.

Serum levels of LH, FSH, $\mathrm{E}_{2}$, and P measured during pretreatment cycles showed the hormonal pattern characteristic of normal follicular maturation, ovulation, and corpus luteum function (Fig. 1). During

TABLE I

Menstrual Cycle Length (mean $\pm S D$ ) before and during Tamoxifen Administration

\begin{tabular}{lccc}
\hline & No treatment & Tamoxifen 1 & Tamoxifen 2 \\
\hline Total length, $d$ & $28.6 \pm 3.6$ & $30.6 \pm 2.3$ & $26.0 \pm 5.1$ \\
Follicular phase, $d$ & $15.8 \pm 2.6$ & $15.4 \pm 1.5$ & $12.2 \pm 4.4$ \\
Luteal phase, $d$ & $13.8 \pm 3.7$ & $15.2 \pm 5.2$ & $13.8 \pm 2.2$ \\
\hline
\end{tabular}
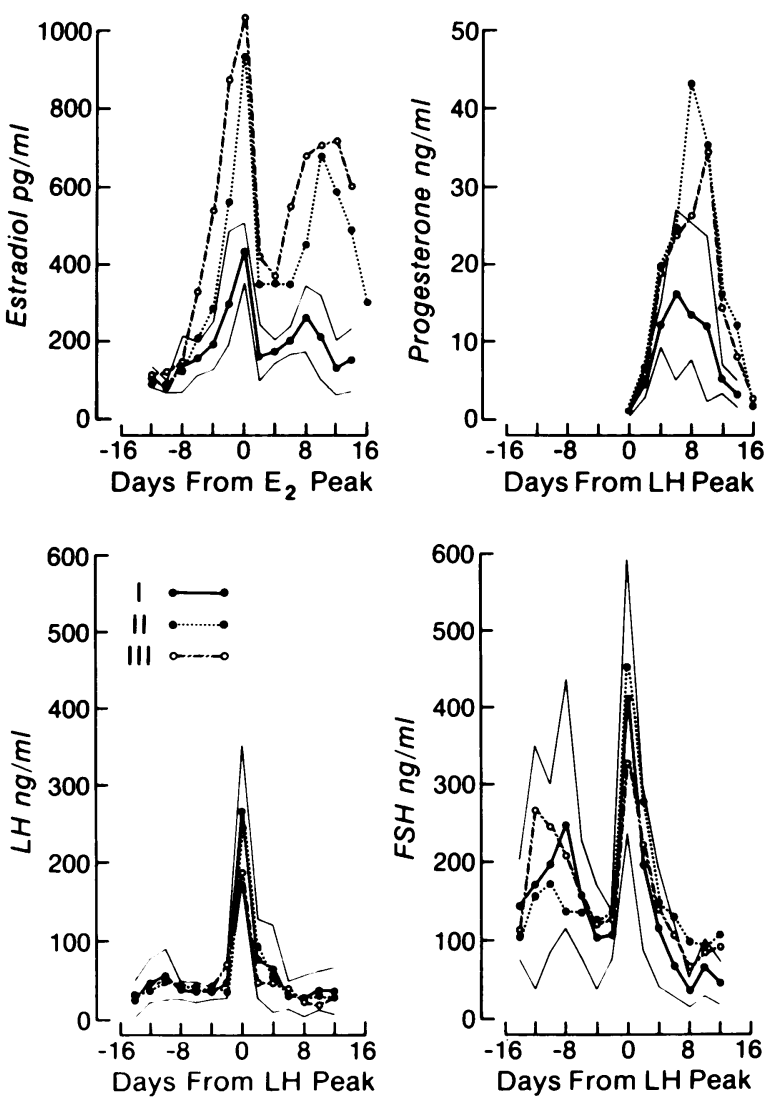

Figure 1 The mean LH, FSH, $\mathrm{E}_{2}$, and $\mathrm{P}$ concentrations for five healthy women during each of two cycles of antiestrogen therapy are shown by the two interrupted lines and are compared with the mean $\pm \mathrm{SEM}$ for the nontreatment cycle, indicated by the area enclosed by the solid lines. LH, FSH, and $\mathrm{P}$ levels are synchronized around the day of the $\mathrm{LH}$ peak, and $E_{2}$ levels are synchronized around the day of the $\mathrm{E}_{2}$ peak.

tamoxifen treatment, serum $\mathrm{E}_{2}$ and $\mathrm{P}$ concentrations were greatly increased over the nontreatment cycle (Figs. 1 and 2). During the first cycle of antiestrogen therapy, three subjects demonstrated hyperestrogenemia and during the second treatment cycle, all five had markedly elevated $\mathrm{E}_{2}$ concentrations. The pattern of $\mathrm{E}_{2}$ secretion was normal, with progressively increasing levels during the second half of the follicular phase followed by a sharp decrease after the midcycle peak and a secondary rise during the luteal phase. Mean serum $E_{2}$ concentrations throughout the tamoxifen cycles were two to three times those observed during the normal cycle (Table II). In several instances, $E_{2}$ levels did not return to basal concentrations before the next episode of presumed ovulation and luteinization (Fig. 2). The pattern of urinary estrogen excretion was like that for serum $\mathrm{E}_{2}$ with a marked preovulatory increase during tamoxifen treatment (Fig. 3). 
TABLE II

Mean \pm SEM Follicular- and Luteal-Phase Serum LH, FSH, PRL, and $E_{2}$ Concentration and Integrated Luteal Phase P Concentrations before and during Tamoxifen Treatment

\begin{tabular}{|c|c|c|c|c|c|c|}
\hline & \multicolumn{2}{|c|}{ Nontreatment } & \multicolumn{2}{|c|}{ Tamoxifen 1} & \multicolumn{2}{|c|}{ Tamoxifen 2} \\
\hline & Follicular & Luteal & Follicular & Luteal & Follicular & Luteal \\
\hline $\mathrm{LH}, n g / m l$ & $39.4 \pm 4.6$ & $46.4 \pm 7.5$ & $39.2 \pm 4.1$ & $40.1 \pm 5.2$ & $48.2 \pm 7.7$ & $35.9 \pm 4.5$ \\
\hline $\mathrm{FSH}, n g / m l$ & $175.7 \pm 19.1$ & $82.4 \pm 15.2$ & $135.2 \pm 7.0$ & $138.1 \pm 12.4^{*}$ & $197.1 \pm 19.1$ & $132.6 \pm 16.5^{*}$ \\
\hline PRL, $n g / m l$ & $8.7 \pm 0.6$ & $11.3 \pm 0.8$ & $9.5 \pm 0.6$ & $9.8 \pm 0.8$ & $8.9 \pm 0.7$ & $9.9 \pm 0.6$ \\
\hline $\mathrm{E}_{2}, p g / m l$ & $198.8 \pm 22.2$ & $196.5 \pm 15.4$ & $335.2 \pm 65.4^{*}$ & $463.5 \pm 45.4^{*}$ & $506.3 \pm 78.9^{*}$ & $585.9 \pm 135.1^{*}$ \\
\hline $\mathrm{P}, n g / m l / c y c l e$ & - & $123.0 \pm 26.9$ & - & $288.1 \pm 76.2 \ddagger$ & - & $246.5 \pm 50.8 \S$ \\
\hline
\end{tabular}

${ }^{*} P=<0.01$ analysis of variance.

$\ddagger P=<0.025$.

$\S P=<0.05$.

Integrated luteal-phase $\mathrm{P}$ concentrations during the antiestrogen cycles were twice those of the control cycle, with mean maximum values $>35 \mathrm{ng} / \mathrm{ml}$ (Table II). The pattern of $\mathrm{P}$ secretion was like that observed

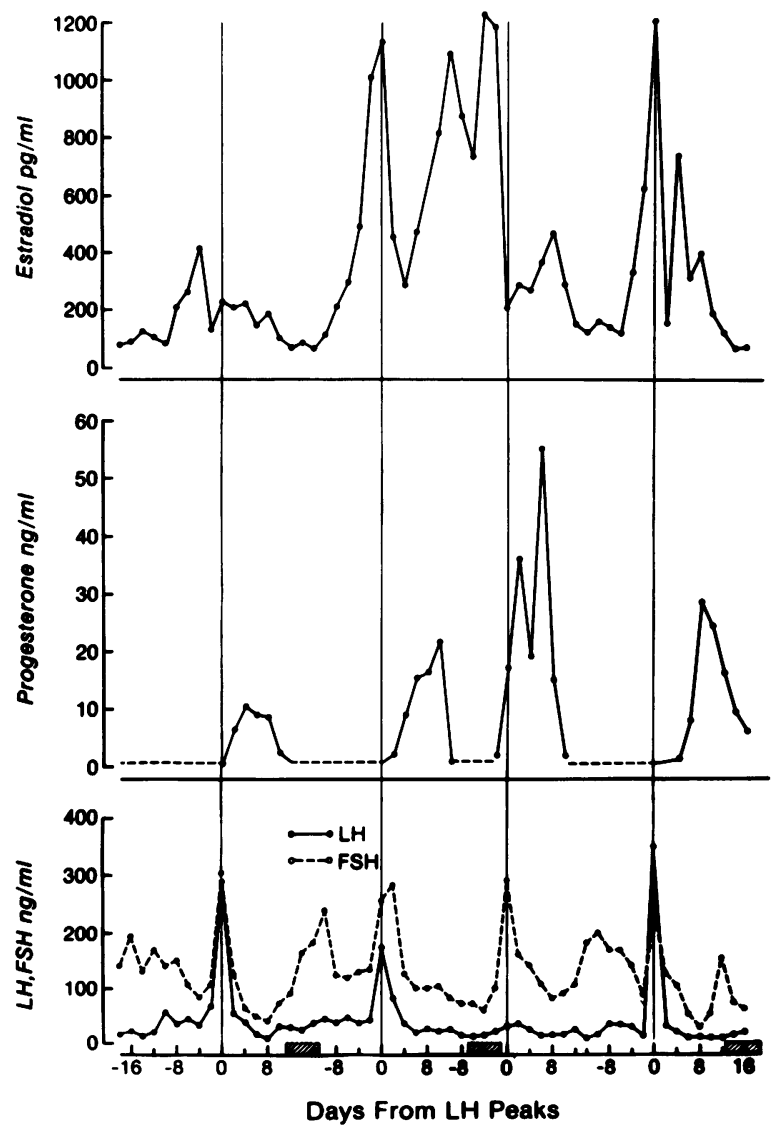

Figure 2 Concentrations of serum LH, FSH, $E_{2}$, and $P$ on alternate days during four consecutive menstrual cycles in one subject. The first, nontreatment cycle was followed by three consecutive cycles of tamoxifen, $10 \mathrm{Mg}$, twice daily. The hormone values are synchronized around the day of the LH peak. The hatched areas indicate menstruation. during the nontreatment cycle, and all values decreased appropriately before menstruation (Figs. 1 and 2).

Concentrations of LH during tamoxifen therapy were not different from the nontreatment cycles, with mean values well within 2 SEM of the control cycle (Fig. 1, Table II). Fig. 4 shows that nearly all individual values during tamoxifen treatment were at or below the maximum value measured in individual subjects during the nontreatment cycle. Despite two to threefold increases in serum $\mathrm{E}_{2}, \mathrm{FSH}$ concentrations during the follicular phase of tamoxifen treatment cycles were not significantly different from control values (Table II, Figs. 1 and 4), but during the luteal phase of tamoxifen cycles, mean FSH concentrations were significantly greater than the values during the nontreatment cycle, $P<0.001$ (Table II).

Serum PRL concentrations during tamoxifen cycles were not significantly different from nontreatment levels, nor were the PRL and TSH responses to TRH significantly different from those measured before antiestrogen treatment (Table II, Fig. 5). By contrast $\mathrm{LH}$ and FSH responses to $\mathrm{GnRH}$ were significantly increased, $P<0.05$ (paired $t$ test) during

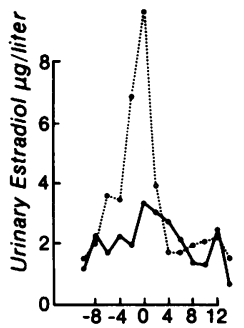

Days from $E_{2}$ Peak

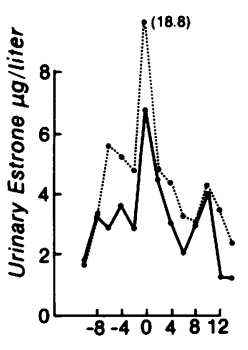

Days from $\mathrm{E}_{2}$ Peak

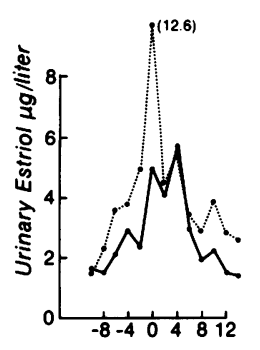

Days from $E_{2}$ Peak
Figure 3 Excretion of $E_{2}$, estrone, and estriol in 12-h overnight urine samples from one patient studied during a menstrual cycle before (solid lines) and while taking tamoxifen (dotted lines). 


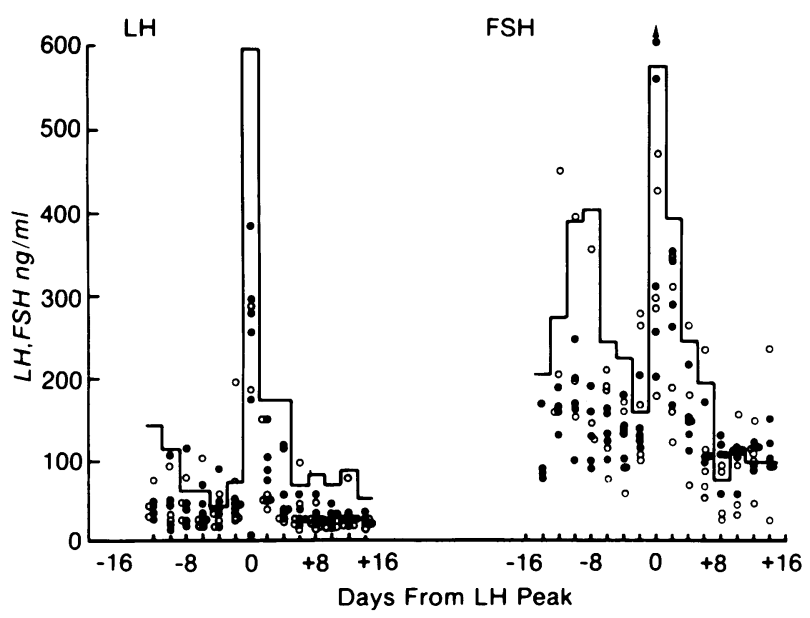

FIGURE 4 All individual LH and FSH values from five subjects during the first $(O)$ and second $(O)$ cycles of tamoxifen treatment are compared with the greatest value measured in any single individual during the nontreatment cycle.

tamoxifen treatment. For LH, this was because of a prolongation of elevated values rather than an accentuation of the acute response (Fig. 6).

No differences could be ascertained in the histologic appearance of endometrial biopsies obtained during the follicular phases of nontreatment and tamoxifen cycles. Luteal-phase endometrial biopsies were done only during the second cycles of tamoxifen therapy. Those biopsies were obtained during the second half of the luteal phase, 8-14 d after the LH peak (Table III). There was a uniform deficiency of changes associated with $\mathrm{P}$ effect and no evidence of
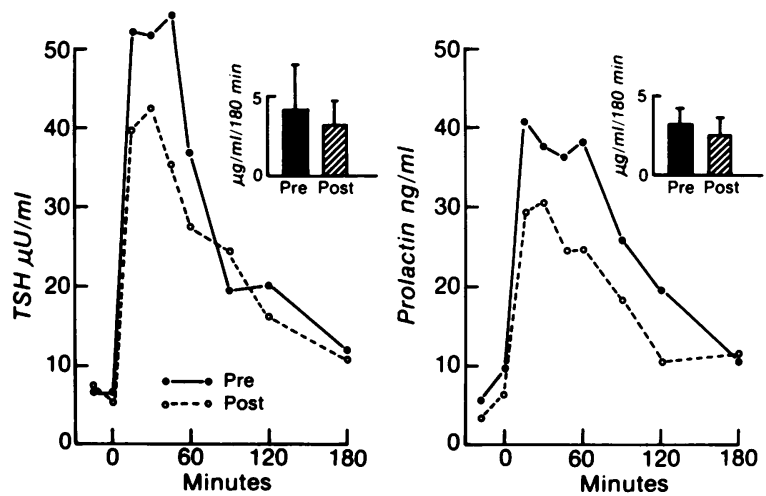

FIgURE 5 The TSH and PRL responses to TRH during the follicular phase of the pretreatment and second tamoxifen treatment cycles. The insets show the integrated hormone response as determined by the method of trapezoids. The vertical lines indicate $2 \mathrm{SD}$. Tests were done on days 9-12 of the follicular phase of the control cycle when serum $E_{2}$ was $80-155$, mean $102 \mathrm{pg} / \mathrm{ml}$, and days $7-10$ of the tamoxifen treatment cycle when serum $\mathrm{E}_{2}$ was $350-1,180$, mean 630 $\mathrm{pg} / \mathrm{ml}$.

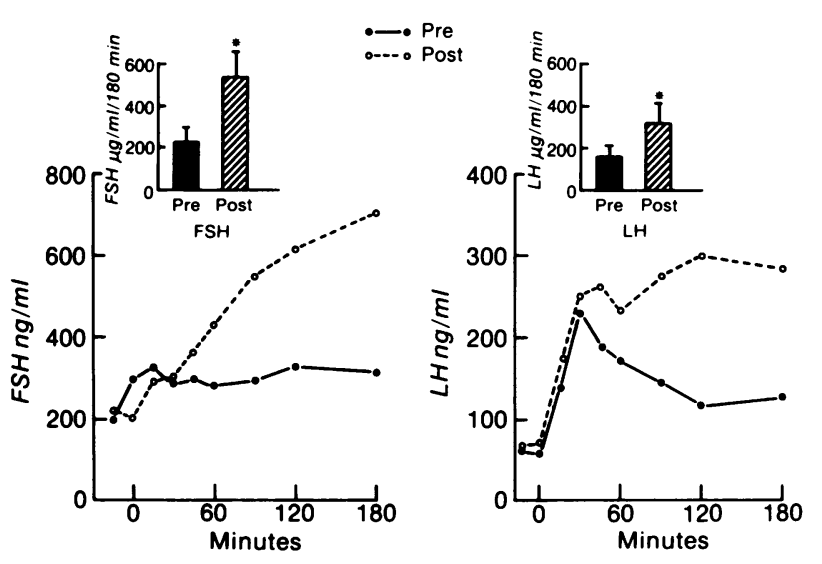

Figure 6 The FSH and LH responses to GnRH during the follicular phase of the pretreatment and second tamoxifen treatment cycles. The insets indicate the integrated responses and the asterisks indicate a significant difference, $P<0.05$ by paired $t$ test analysis. Tests were done at the same time as TRH stimulation, Fig. 5 .

histologic progression beyond that expected on day 8 of a normal menstrual cycle (Table III).

\section{DISCUSSION}

Tamoxifen is one of a group of nonsteroidal compounds, amino-ether derivatives of polycyclic phenols, that act as estrogen antagonists. Antiestrogens were initially investigated as antifertility agents, but have had their greatest clinical usefulness as inducers of follicular maturation in amenorrheic or oligomenorrheic women. In most circumstances, a 5-d course of antiestrogen treatment results in increased $\mathrm{LH}$ and FSH secretion and stimulation of follicle development (3). An extensive literature exists concerning the clinical and endocrine consequences of short-term antiestrogen used for fertility induction. There is little information on the consequences of prolonged antiestrogen treatment in women. In men, the longterm administration of clomiphene citrate resulted in an increase in both LH and FSH which in healthy subjects was accompanied by increased testosterone secretion (10).

Initially, antiestrogen action was explained by simple competition for cytoplasmic estrogen receptors in target tissues. Later studies showed that tamoxifen and related compounds demonstrated some estrogenlike effects (11). It followed that, like natural estrogens, antiestrogens underwent translocation from the cytoplasm to the nucleus. In contrast to $17 \beta$-estradiol, the antiestrogen-receptor complex exhibited long-term nuclear retention, resulting in early estrogen-like responses and later antagonism of estrogen action (12). This antagonism has been explained by failure of the antiestrogen-receptor complex to replenish the cyto- 
TABLE III

Histologic Staging of Endometrial Biopsies before and during the Second Cycle of Tamoxifen Treatment

\begin{tabular}{lllcl}
\hline Subject & Biopsy & Treatment & Days from LH peak & Histology \\
\hline I & Follicular & None & -8 & Proliferative \\
& Follicular & Tam & -6 & Proliferative \\
& Luteal & Tam & +11 & Secretory +7/8 \\
II & Follicular & None & -4 & Proliferative \\
& Follicular & Tam & -8 & Proliferative \\
& Luteal & Tam & +13 & Secretory +5 \\
& Follicular & None & -12 & Menstrual \\
III & Follicular & Tam & -1 & Proliferative \\
& Luteal & Tam & +8 & Secretory +4 \\
& Follicular & None & -4 & Proliferative \\
IV & Follicular & Tam & -3 & Proliferative \\
& Luteal & Tam & +14 & Secretory +8 \\
& Follicular & None & -9 & Proliferative \\
& Follicular & Tam & +3 & Secretory +3 \\
V & Luteal & Tam & +10 & Secretory +8 \\
& & &
\end{tabular}

plasmic estrogen receptor (11), a postulate that is the subject of some controversy (13).

The cytoplasmic progesterone receptor has been demonstrated to be estrogen-dependent in the chick oviduct and other tissues including uterus, endometrium, dimethylbenzanthracene-induced mammary tumors, and human breast cells in tissue culture (14-17). Since tamoxifen can block the estrogen-induced increases in progesterone receptor $(17,18)$, one might anticipate that antiestrogens would exhibit $\mathbf{P}$ antagonism as well.

The daily administration of tamoxifen to healthy women during the menstrual cycle resulted in the exaggerated secretion of $E_{2}$ and $P$ in a pattern consistent with normal but augmented follicular maturation. That this occurred in the absence of concomitant increases in gonadotropin secretion was the most striking and unexpected feature of this study. It differs from the effect of $5 \mathrm{~d}$ of treatment with clomiphene during the normal menstrual cycle which resulted in increased serum concentrations of both $\mathrm{E}_{2}$ and gonadotropins (19). The mechanism responsible for hyperestrogenemia in the absence of increased gonadotropin concentrations is open to speculation. The concomitant increase in urinary estrogen and the sharp decrease in serum $E_{2}$ after the midcycle peak suggests that the elevated serum levels reflect increased secretion rather than markedly altered metabolism. Other explanations for increased estrogen production include changes in estrogen and/or $\mathrm{P}$ action in the ovarian microenvironment, altered regulation of follicle atresia, or altered gonadotropin action as a consequence of changes in ovarian LH and FSH receptors.

The increased estrogen and $P$ secretion during tamoxifen therapy could reflect enhanced gonadotropin stimulation of a single maturing follicle or could be the result of a simultaneous maturation of multiple follicles. Direct anatomic observations are needed to substantiate either of these alternatives. The presence of multiple preantral follicles resulting from diminished follicle atresia is one explanation for the apparent increase in gonadotropin action in the absence of increased gonadotropin concentrations. Ross and coworkers have shown that preantral follicle development is independent of gonadotropins, and is stimulatable by estrogens (20). Furthermore, in the immature hypophysectomized female rat, estrogen administration decreased the number of atretic follicles, an effect that was shared by the antiestrogen CI-628 (21). It is possible that daily treatment with tamoxifen exerted a predominantly estrogen-like action in the ovary, resulting in diminished follicle atresia. A decrease in atresia might provide more than one follicle for stimulation by normal concentrations of circulating gonadotropin.

There is little that is histologically characteristic of the endometrium during the preovulatory phase of the menstrual cycle. It therefore may not be surprising that no differences were noted in the follicularphase biopsies during control and tamoxifen treatment cycles. Histologic criteria for dating of the lutealphase endometrium are generally accepted. All biop- 
sies obtained during the luteal phase of tamoxifen cycles demonstrated a maturation delay of 2-8 d despite supranormal $\mathrm{P}$ and $\mathrm{E}_{2}$ concentrations (Table III).

The $P$ receptor concentration in human endometrium varies systematically during the menstrual cycle with maximum levels at midcycle (22). This observation has been interpreted to indicate that the endometrial $P$ receptor is estrogen dependent. Antiestrogen interference with estrogen-mediated synthesis of $P$ receptor is the most attractive explanation for the observation of delayed endometrial maturation in women taking tamoxifen. These studies may provide the first morphologic demonstration of that effect in humans. Obviously, direct studies of receptor content are needed.

One alternative explanation of this observation deserves comment. The administration of high doses of estrogens during the luteal phase results in reduced corpus luteum $\mathrm{P}$ secretion, suggesting a regulatory role for estrogen in the corpus luteum (23-25). This has been proposed as a mechanism for the contraceptive effect of single, large doses of estrogen. Since estrogen administration results in diminished corpus luteum function, interference with estrogen action might result in increased $P$ secretion.

Pituitary gonadotropin secretion is suppressed by $\mathrm{E}_{2}$ administration to either pre-or postmenopausal women, and most studies indicate that FSH is more sensitive to $E_{2}$ feedback than $\operatorname{LH}(26,27)$. The two to threefold increase in serum $\mathrm{E}_{2}$ during tamoxifen treatment failed to suppress basal FSH or LH concentrations (Table II, Fig. 4), evidence for an antiestrogenic action of tamoxifen at the level of the hypothalamus or pituitary gland.

The enhanced gonadotropin responses to GnRH administered during tamoxifen treatment were not consistent with the effects of the drug on basal LH and FSH concentrations. Estrogens have been shown to either increase or decrease the gonadotropin response to GnRH depending on dose and duration of administration (28-30). Other studies have shown the gonadotropin responses to $\mathrm{GnRH}$ were diminished by infusions of $17 \beta$-estradiol that increased circulating $\mathrm{E}_{2}$ concentrations to levels comparable to those obtained during tamoxifen treatment $(27,29)$. Likewise, chronic estrogen administration reduced or obliterated GnRH responsiveness (28). By contrast, the hyperestrogenemia that accompanied tamoxifen therapy did not diminish the LH or FSH response to GnRH but rather appeared to prolong gonadotropin secretion (Fig. 6). This contrasts with the observation that clomiphene blocked the enhanced gonadotropin responses to GnRH that occur during those phases of the menstrual cycle characterized by higher circulating estrogen concentrations (30). These disparate effects of tamoxifen on basal and GnRH-stimulated gonadotropin secretion are not readily explainable, but reinforce the impression that the actions of estrogen antagonists may vary among themselves and in different tissues.

Estrogen administration results in increased serum PRL concentrations and PRL responses to TRH are greater during the late follicular phase of the menstrual cycle, presumably related to higher circulating $E_{2}$ levels $(31,32)$. There was no significant change in basal or stimulated PRL secretion during tamoxifen administration (Table II, Fig. 5). Since serum $\mathrm{E}_{2}$ concentrations were 3 to 10-fold greater during tamoxifen administration, there was evidence for a predominant antiestrogen action on basal and stimulated PRL secretion.

These studies have raised important questions regarding the use of antiestrogens in the treatment of premenopausal breast cancer patients. Since estrogen administration to premenopausal women with breast cancer is generally avoided, it follows that there should be reluctance to intentionally increase serum $\mathrm{E}_{2}$ concentrations unless there was evidence that estrogen antagonism was predominant at the site of malignancy. There is as yet little information upon which to base that judgement. Clinically, antiestrogens have been used primarily in the treatment of metastatic disease in postmenopausal women. There are several reports of clinical responses in premenopausal women but no large, systematic studies (32). There are no readily available methods for measurement of tamoxifen in blood and there is insufficient information from studies of tamoxifen inhibition of the growth of breast cancer cells in tissue culture to determine the critical antiestrogen/estrogen ratio. Whereas our studies in premenopausal women suggest that antiestrogen action might vary in different target tissues, there was evidence for estrogen antagonism at the hypothalamus and pituitary as well as the endometrium, providing some reason to believe that an antiestrogen effect might also prevail at the level of the malignant cell.

\section{ACKNOWLEDGMENTS}

Our thanks to Dr. Christopher Longcope for measurement of the urinary estrogens.

These studies were supported by National Institutes of Health grant CA17649 from the National Cancer Institute, and RR59 from the Clinical Research Centers Program, Division of Research Resources.

\section{REFERENCES}

1. Kiang, D. T., and B. J. Kennedy. 1977. Tamoxifen (antiestrogen) therapy in advanced breast cancer. Ann. Intern. Med. 87: 687-690.

2. Moseson, D. L., G. H. Sasaki, W. G. Kraybill, B. S. Leung, C. E. Davenport, and W. S. Fletcher. 1978. The use of antiestrogens tamoxifen and nafoxidine in the treatment 
of human breast cancer in correlation with estrogen receptor values. A Phase II Study. Cancer. 41: 797-800.

3. Lunan, C. B., and A. Klopper. 1975. Antioestrogens: a review. Clin. Endocrinol. 4: 551-572.

4. Odell, W. D., G. T. Ross, and P. L. Rayford. 1967. Radioimmunoassay for luteinizing hormone in human plasma or serum. Physiological studies. J. Clin. Invest. 46: 248-255.

5. Cargille, C. M., and P. L. Rayford. 1970. Characterization of antisera for follicle stimulation hormone. J. Lab. Clin. Med. 25: 1030-1040.

6. Utiger, R. D. 1965. Radioimmunoassay of plasma thyrotropin. J. Clin. Invest. 44: 1277-1286.

7. Sinha, Y. N., F. W. Selby, U. J. Lewis, and W. P. Vanderlann. 1973. A homologous radioimmunoassay for human prolactin. J. Clin. Endocrinol. Metab. 36: 509-513.

8. Korenman, S. G., R. H. Stevens, L. A. Carpenter, M. Robb, G. D. Niswender, and B. M. Sherman. 1974. Estradiol radioimmunoassay without chromatography: procedure, validation and normal values. J. Clin. Endocrinol. Metab. 38: 718-720.

9. Noyes, R. W., A. T. Hertig, and J. Rock. 1950. Dating the endometrial biopsy. Fertil. Steril. 1: 1-25.

10. Santen, R. J., J. M. Leonard, R. J. Sherins, H. M. Gandy, and C. A. Paulsen. 1971. Short- and long-term effects of clomiphene citrate on the pituitary-testicular axis. $J$. Clin. Endocrinol. Metab. 33: 970-979.

11. Clark, J. H., E. J. Peck, and J. N. Anderson. 1974. Oestrogen receptors and antagonism of steroid hormone action. Nature (Lond.). 252: 446-448.

12. Clark, J. H., J. W. Hardin, H. A. Padykula, and C. A. Cardasis. 1978. Role of estrogen receptor binding and transcriptional activity in the stimulation of hyperestrogenism and nuclear bodies. Proc. Natl. Acad. Sci. U. S. A. 75: 2781-2784.

13. Koseki, Y., D. T. Zava, G. C. Chamness, and W. L. McGuire. 1977. Estrogen receptor translocation and replenishment by the antiestrogen tamoxifen. Endocrinology. 101: 1104-1110.

14. Toft, D. O., and B. W. O'Malley. 1972. Target tissue receptors for progesterone: the influence of estrogen treatment. Endocrinology. 90: 1041-1045.

15. Rao, B. R., W. G. Wiest, and W. M. Allen. 1973. Progesterone receptor in rabbit uterus. 1. Characterization and estradiol-17 $\beta$ augmentation. Endocrinology. 92: 1229-1240.

16. Horwitz, K. B., and W. L. McGuire. 1977. Progesterone and progesterone receptors in experimental breast cancer. Cancer Res. 37: 1733-1738.

17. Horwitz, K. B., and W. L. McGuire. 1978. Estrogen control of progesterone receptor in human breast cancer. Correlation with nuclear processing of estrogen receptor. J. Biol. Chem. 253: 2223-2228.

18. Lippman, M., G. Bolan, and K. Huff. 1976. The effects of estrogens and antiestrogens on hormone-responsive human breast cancer in long-term tissue culture. Cancer Res. 36: 4595-4601.

19. Vandenberg, G., and S. S. C. Yen. 1973. Effect of antiestrogenic action of clomiphene during the menstrual cycle: evidence for a change in the feedback sensitivity. J. Clin. Endocrinol. Metab. 37: 356-365.

20. Ross, G. T. 1974. Gonadotropins and preantral follicular maturation in women. Fertil. Steril. 25: 522-543.

21. Harman, S. M., J-P. Louvet, and G. T. Ross. 1975. Interaction of estrogen and gonadotrophins on follicular atresia. Endocrinology. 96: 1145-1152.

22. Pollow, K., M. Schmidt-Gollwitzer, and J. NevinnyStickel. 1977. Progesterone receptors in normal human endometrium and endometrial carcinoma. In Progesterone Receptors in Normal and Neoplastic Tissues. W. L. McGuire, J. P. Raynard, and E. M. Baulieu, editors. Raven Press, New York. 313-338.

23. Karsch, F. J., L. C. Krey, R. F. Weick, D. J. Dierschke, and E. Knobil. 1973. Functional luteolysis in the Rhesus monkey: the role of estrogen. Endocrinology. 92: 11481152.

24. Gore, B. Z., B. V. Caldwell, and L. Speroff. 1973. Estrogeninduced human luteolysis. J. Clin. Endocrinol. Metab. 36: 615-617.

25. Lehmann, Just-Nastansky I., B. Behrendt, P-J. Czygan, and G. Bettendorf. 1975. Effect of post-ovulatory administered oestrogens on corpus luteum function. Acta Endocrinol. 79: 329-336.

26. Wallach, E. E., A. W. Root, and C. R. Garcia. 1970. Serum gonadotropin responses to estrogen and progestogen in recently castrated human females. J. Clin. Endocrinol. Metab. 32: 766-771.

27. Wise, A. J., M. S. Gross, and D. S. Schalch. 1973. Quantitative relationships of the pituitary-gonadal axis in postmenopausal women. J. Lab. Clin. Med. 81: 28-36.

28. Yen, S. S. C., G. Bandenberg, and T. M. Siler. 1974. Modulation of pituitary responsiveness to LRF by estrogen. J. Clin. Endocrinol. Metab. 39: 170-177.

29. Keye, W. R., Jr., and R. B. Jaffe. 1974. Modulation of pituitary gonadotropin response to gonadotropin-releasing hormone by estradiol. J. Clin. Endocrinol. Metab. 38: 805-810.

30. Wang, C. F., and S. S. C. Yen. 1975. Direct evidence of estrogen modulation of pituitary sensitivity to luteinizing hormone-releasing factor during the menstrual cycle. $J$. Clin. Invest. 55: 201-204.

31. Vekemans, M., and C. Robyn. 1975. The influence of exogenous estrogen on the circadian periodicity of circulating prolactin in women. J. Clin. Endocrinol. Metab. 40: 886-889.

32. Boyd, A. E., III, and F. Sanchez-Franco. 1977. Changes in the prolactin response to thyrotropin-releasing hormone (TRH) during the menstrual cycle of normal women. J. Clin. Endocrinol. Metab. 44: 985-989. 